\title{
PRODUÇÃO DE CARNE BOVINA ORGÂNICA: UMA AVALIAÇÃO DOS IMPACTOS SOCIOECONÔMICOS NA REGIÃO DO PANTANAL DO BRASIL
}

\author{
Daniel Almeida Lopes Neves* \\ João Paulo Guimarães Soares ${ }^{* *}$ \\ José Márcio Carvalho***
}

RESUMO: O objetivo deste trabalho foi avaliar os impactos sociais da transição agroecológica da produção de carne bovina convencional para orgânica, em unidades de produção no Brasil, pelo método Ambitec, desenvolvido pela Embrapa Meio Ambiente. Foram avaliadas nove unidades de produção no Estado do Mato Grosso do Sul que integram os únicos 18 produtores brasileiros de carne bovina orgânica. Os dados para o levantamento foram obtidos no segundo trimestre de 2012, por meio de questionários aplicados aos representantes das propriedades avaliadas que atribuíram a cada variável estudada um valor que representou a alteração proporcionada pela transição agroecológica dos sistemas. Após a inserção dos coeficientes de alteração de cada variável dos indicadores por unidade de produção, o coeficiente de impacto foi automaticamente calculado por meio da planilha Ambitec. O manejo orgânico da produção, quando comparado ao convencional, proporcionou um impacto social positivo, sendo as maiores contribuições proporcionadas pelos efeitos positivos dos seguintes indicadores: Capacitação $(\mu=9,69)$, Geração de renda $(\mu=13,75)$, Dedicação e Perfil do Responsável $(\mu=12,86)$ e o Relacionamento Institucional $(\mu$ $=12,19)$. Na análise de agrupamento, os produtores 1,6 e 7 obtiveram maior média no índice geral do impacto social da produção orgânica $(\mu=6,83)$.

PALAVRAS-CHAVE: Agroecologia; Carne orgânica; Emprego; Renda; Saúde; Sustentabilidade.

\section{PRODUCTION OF ORGANIC BEEF: EVALUATION OF THE SOCIOECONOMIC IMPACTS ON THE BRAZILIAN PANTANAL REGION}

\footnotetext{
Economista; Mestre em Agronegócios pela Universidade de Brasília (UnB), Brasil.

** Doutor em Zootecnia (Produção Animal) pela Universidade Estadual Paulista Júlio de Mesquita Filho (UNESP/ Jaboticabal); Pesquisador A da Empresa Brasileira de Pesquisa Agropecuária - EMBRAPA Cerrados, Brasil.

*** Doutor em Comércio Internacional pela University of Reading, Inglaterra; Docente de Internacionalização de Negócios, na Universidade de Brasília (UnB), Brasil; E-mail: jmcarvalho1708@gmail.com
} 
ABSTRACT: The social impacts of agro-ecological transition from the production of conventional beef to organic beef are evaluated in Brazilian production units, by the Ambitec method developed by the Embrapa Meio Ambiente. Nine production units were evaluated in the state of Mato Grosso do Sul, Brazil. They integrated the only 18 Brazilian producers of organic beef. Data were collected in the second trimester of 2012 by questionnaires applied to representatives of farms who attributed a mark which represents alteration provided by the systems' agro-ecological transition, to each variable analyzed. After inserting the alteration coefficients of each variable of indicators per production unit, impact coefficient was immediately calculated by an Ambitec sheet. When compared to the conventional one, the organic management of production provided positive social impact, with the highest contributions provided by the positive effects of the following indexes: Capacity $(\mu=9.69)$, generation of earnings $(\mu=13.75)$, Dedication and Profile of the Agent $(\mu=12.86)$ and Institutional Relationship $(\mu=12.19)$. In the case of grouping analysis, producers 1,6 and 7 had the highest average in the general index of social impact of organic production $(\mu=6.83)$.

KEY WORDS: Agro-Ecology; Organic Beef; Employment; Earnings; Health; Sustainability.

\section{INTRODUÇÃO}

Os padrões de evolução da agricultura no final do século 19 e início do século 20 tendiam a levar ao crescimento da propriedade agrícola, esta era uma tendência encorajada pois se acreditava que unidades de produção maiores poderiam se apropriar melhor de progressos tecnológicos (BUAINAIN et al., 2005).

Esta tendência trouxe avanços mas gerou, também, resultados negativos nos aspectos sociais e ambientais (PAULUS; SCHLINDWEIN, 2001). Esta modernização, na visão de Gehlen (2004), levou ao quase desaparecimento de sistemas autóctones de produção e ao surgimento de sistemas dependentes de recursos externos.

Não se pode confundir crescimento econômico com desenvolvimento. Denardi et al. (2000) ressaltam que diversos problemas, como por exemplo piora na qualidade de vida, vieram com o crescimento econômico desequilibrado. Paulus e Schlindwein (2001) advogam uma agricultura ecologicamente correta, viável 
economicamente, mais justa e mais humana. Trata-se da linha que pode ser chamada de desenvolvimento rural sustentável.

A agricultura em escala industrial tem uma importância muito grande para a balança comercial do país. Na visão de Binotto e Nakayama (2009), o agronegócio brasileiro ao se tornar mais competitivo se tornou também uma referência no cenário internacional assumindo o papel de um dos principais atores.

A carne bovina produzida de forma convencional aparece como um dos protagonistas no cenário do agronegócio brasileiro. O país conta com 209 milhões de cabeças de bovinos e chega levar ao abate 28 milhões de cabeças (ABIEC, 2012; IBGE, 2012).

Já segundo as duas únicas associações produtoras de carne bovina orgânica no Brasil, o abate anual é de 13.800 cabeças/ano, oriundas de apenas 18 produtores certificados. A representação do abate de carne bovina orgânica no abate total do Brasil é de $0,05 \%$ e a comercialização é exclusivamente no mercado interno (FIGUEIREDO; SOARES, 2012).

O mercado consumidor vem mudando nos últimos anos e é este um determinante para os padrões de produção no Brasil e no mundo. Surgem novos nichos de mercado e esta é uma realidade também para a carne bovina. O setor tem que se adaptar aos novos segmentos de mercado onde os compradores estão mais interessados em conhecer a garantia de qualidade e a origem da carne consumida.

De acordo com Araújo e Mendonça (2009), as constantes restrições não tarifárias e as demandas sociais impostas às carnes destinadas à exportação acabam forçando os pecuaristas a construir alternativas e a buscar criar uma imagem favorável às práticas de responsabilidade social e ambiental.

Diferentes trabalhos têm sido desenvolvidos em sistemas de produção orgânica animal, conforme Soares et al. (2011). Figueiredo e Soares (2012), entretanto, não mensuraram de forma quantitativa e associativa o conjunto dos impactos sociais. A avaliação dos impactos sociais pode ser realizada através do uso do Sistema Ambitec (Rodrigues; Campanhola, 2003), utilizado anualmente no contexto institucional de pesquisa e desenvolvimento na Embrapa, e validado durante o período 2001-2008 (Balanço social da pesquisa agropecuária brasileira, 2006; 2009; Rodrigues et al., 2006), sendo um instrumento importante para este tipo de mensuração. 
O presente trabalho teve como objetivo avaliar os impactos sociais da transição agroecológica da produção de carne bovina convencional para orgânica, em unidades de produção no Brasil.

\section{MATERIAL E MÉTODOS}

O levantamento foi realizado no município de Campo Grande, capital do Estado de Mato Grosso do Sul, localizado na região Centro-Oeste brasileira. Os dados para o levantamento foram obtidos com nove produtores de gado de corte orgânico já certificados pelo IBD (Instituto Biodinâmico). As entrevistas foram feitas no período de maio de 2012 na sede da ABPO (Associação Brasileira de Pecuária Orgânica). Os produtores utilizavam a pecuária convencional e fizeram a transição agroecológica para a produção orgânica durante os anos anteriores no período previsto pela certificadora. O levantamento dos dados da pesquisa abrangeu o período de transição de 2008-2012, focados nas características e resultados obtidos na nova forma de produção.

O sistema de avaliação de impactos sociais utilizado foi o Ambitec-social (Rodrigues et al., 2003), desenvolvido pela Embrapa Meio Ambiente e composto por um conjunto de planilhas eletrônicas (MS Excel), que representam os seguintes aspectos sociais estudados: i) Emprego; ii) Economia; iii) Saúde; e iv) Gestão e Administração, que juntos envolvem quatorze indicadores (RODRIGUES, 2006).

Os indicadores representam as matrizes de ponderação automatizadas que são compostas por suas variáveis, que são mensuradas com base no coeficiente de alteração, ou seja, pela atribuição, a cada variável estudada, de um valor que representa a alteração proporcionada pela implementação da tecnologia, em que o coeficiente +3 indica uma grande influência positiva no componente; +1 moderada influência positiva no componente; 0 componente inalterado; -1 moderada influência negativa no componente; e -3 grande influência negativa no componente (RODRIGUES et al., 2003; TUPY; PRIMAVESI, 2006).

Nas entrevistas com os agricultores foi utilizada a própria planilha do Ambitec - social, impressa e levada ao campo, na qual, conforme o questionamento 
feito a cada agricultor avaliado, foram atribuídos os valores de $-3 \mathrm{a}+3$, inseridos na respectiva variável de cada indicador. Após a coleta das informações, antes e depois da adoção do processo de transição para o manejo orgânico, os coeficientes de alteração obtidos foram inseridos nas células das matrizes de avaliação de impacto social, conforme o grau de alteração proporcionado pela tecnologia, e foram direcionados para atender à escala de ocorrência dessa alteração. Essa escala varia entre pontual, quando o efeito se restringiu ao ambiente de implantação da tecnologia; local, quando o efeito se fez sentir fora do ambiente da tecnologia, mas restrito aos limites da unidade produtiva; e entorno, quando o impacto gerado ultrapassou os limites da unidade produtiva.

Além da escala de ocorrência, os dados inseridos nas planilhas também sofrem influência dos fatores de ponderação, que variam conforme o número de variáveis que formam um determinado indicador e conforme sua importância para a formação do indicador. Essas ponderações juntas somam uma unidade; contudo, se a variação do componente significa um impacto favorável, a soma é positiva, se representar um impacto negativo, a soma é negativa (RODRIGUES et al., 2003).

Portanto, depois de inserir os coeficientes de alteração, o coeficiente de impacto desse indicador é automaticamente calculado com uso do sistema, em função da escala de ocorrência e do fator ponderal, podendo variar de +15 a -15 , a depender do direcionamento do impacto, se benéfico ou prejudicial, respectivamente. O Ambitec também compõe um gráfico para cada indicador, bem como os agrega para compor o índice geral de impacto ambiental e seu respectivo gráfico. Ao final de todas as coletas, os dados de todos os produtores foram organizados em uma tabela, para que fosse possível a obtenção das médias dos componentes avaliados e a posterior análise descritiva.

$\mathrm{Na}$ análise estatística, foi aplicada a técnica de análise de agrupamento de Cluster para agrupar os produtores segundo o resultado dos indicadores de impacto ambiental. A medida de similaridade adotada foi a "Distância Euclidiana Quadrática" e o método aglomerativo utilizado foi o método hierárquico de ligação de Ward. De acordo com Hair et al. (2005), este método busca fazer agrupamentos hierárquicos, onde uma medida de similaridade é usada para coalescer grupos; comumente é feita através da soma dos quadrados de todas as variáveis entre dois agrupamentos. 
Devido ao fato do número de elementos da amostra ser $\mathrm{n}=9$ e não terem comportamento compatível com a distribuição normal foi adotado o teste não paramétrico. Os testes não paramétricos são estatisticamente menos robustos, porém estes se revelam mais eficazes quando não se validam os pressupostos para a aplicação de testes paramétricos.

Para a análise dos dados obtidos, foi utilizado o programa de tratamento estatístico SPSS (Statistical Package for the Social Sciences), para Windows, versão 19.0 e software livre R versão 2.14 .

\section{RESULTADOS E DISCUSSÃO}

Foi avaliada a variação dos índices de impactos sociais, observados nos período em que os produtores não utilizavam as tecnologias de manejo orgânico, conduzindo o manejo da pecuária bovina de forma convencional e depois quando receberam a certificação para a produção da pecuária bovina orgânica. Conforme pode ser observado na Figura 1, os valores obtidos em cada propriedade segundo os produtores, em uma visão geral, apresentaram diferenças entre os períodos de antes e após a conversão para o sistema orgânico, principalmente o produtor 03 , que apresentou a maior variação entre o sistema convencional $(\mu=-3,45)$ e o orgânico $(\mu=6,20)$.

A maior variação para o produtor 03 é devida à não dedicação às três etapas da produção de carne orgânica (cria, recria e engorda). A propriedade é arrendada de terceiros e a atividade principal da propriedade é exclusivamente de recria, o que se diferencia das demais propriedades que desenvolvem as atividades de cria, recria e engorda, sobretudo em relação às questões sociais avaliadas pelo método Ambitec, em que são inseridos índices específicos sobre a mão de obra utilizada na propriedade como, por exemplo, perfil do proprietário, qualidade do emprego e capacitação do trabalhador. Estas não são atendidas pelo produtor mencionado, além da mão de obra contratada não ser regulamentada, sendo os funcionários contratados como diaristas. 


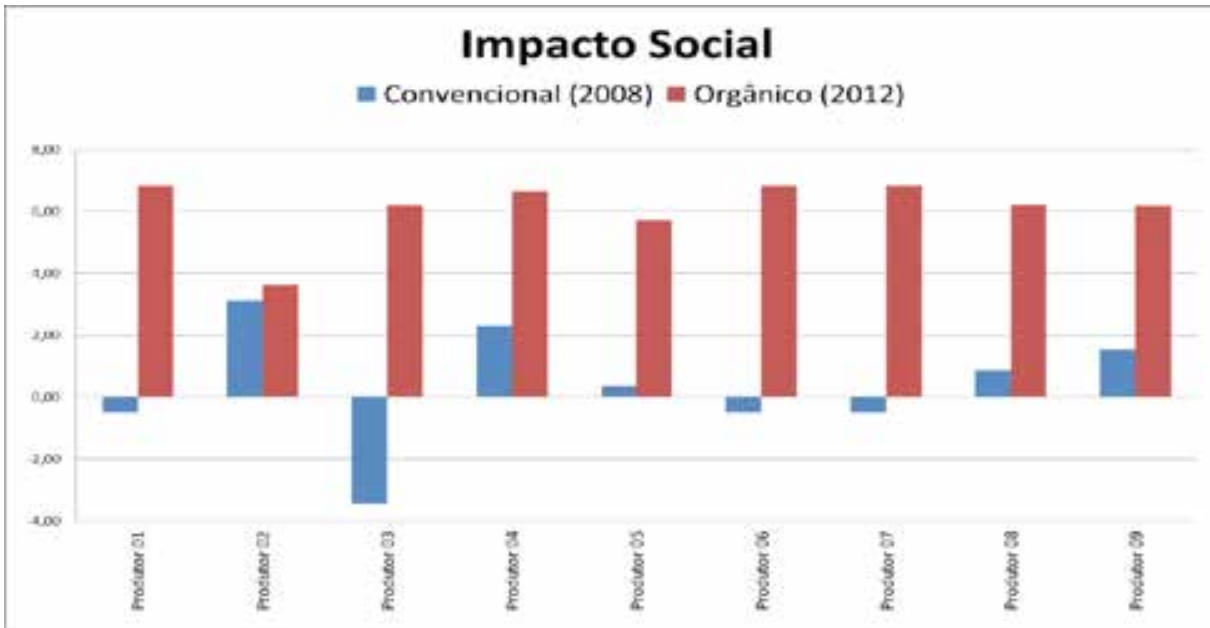

Figura 1. Variação nos índices de impacto social dos produtores entrevistados no sistema convencional (2008) e no sistema orgânico (2012) de carne bovina.

Os resultados observados para todos os outros produtores não apresentaram variações, refletindo a legislação trabalhista já em andamento no Brasil, onde o registro dos trabalhadores com carteira assinada é obrigatório e apenas referendado na IN 46 de produção orgânica. Os índices com as variações entre os nove produtores da $\mathrm{ABPO}$ podem ser explicados devido às diferentes formas de administração e perfil do proprietário. Pode-se destacar ainda notadamente a diferença entre o processo convencional $(\mu=0,37)$ e o processo de produção orgânico $(\mu=6,12)$, obtendo uma variação média de $(\mu=5,76)$ entre os dois processos de produção estudados.

Barreto (2010), ao analisar os valores sociais na pesquisa realizada sobre o manejo agroecológico da caatinga em unidades de produção familiar no RN, obteve o índice geral médio de $(\mu=5,23)$. Silva (2011), ao analisar a produção orgânica em unidades familiares no semiárido brasileiro, apresentou o valor de $(\mu=5,25)$ no índice geral médio de impacto social. Em pesquisa realizada para a pecuária leiteira orgânica na agricultura familiar na região de Votuporanga (SP), Rodrigues (2006), ao analisar os impactos sociais, obteve o índice geral médio de $(\mu=4,68)$. Os índices encontrados nas três pesquisas são próximos, mas pode-se concluir que, com o passar dos anos, este índice tem se elevado, demonstrando a evolução da agricultura orgânica nas pesquisas sobre os impactos sociais. 
Todos os índices de impacto social de produtores obtidos no presente trabalho podem ser encontrados nas Tabelas 1 e 2 . Analisando a variação entre $o$ índice geral médio na produção convencional $(\mu=0,37)$ e o índice quando os pecuaristas recebem a certificação para a produção orgânica $(\mu=6,12)$, a variação entre os dois índices apresenta-se na ordem de $(\mu=5,76)$.

Analisando o resultado obtido entre a pecuária convencional e a pecuária orgânica nota-se que a produção orgânica faz com que a preocupação com a questão social se torne mais evidente, devido principalmente à IN 46 que, junto ao IBD, faz cumprir as leis trabalhistas. Sendo que nos impactos sociais não só a mão de obra empregada nas propriedades é referenciada, o método Ambitec considera na análise o perfil do proprietário, que muito contribuiu para a elevação do índice geral, onde se apresentou um grande aumento da dedicação do pecuarista com a propriedade na produção orgânica.

A contribuição individual de cada um dos indicadores na geração do impacto social positivo está associada diretamente ao impacto econômico positivo. Inicialmente todos os indicadores foram alterados positivamente, muito embora alguns com maiores expressividades do que outros. Dentre os fatores que mais contribuíram para o impacto social positivo, podem-se destacar a geração de renda do estabelecimento, o valor da propriedade, a dedicação e o perfil do responsável e o relacionamento institucional.

Com o resultado apresentado fica evidente que a produção orgânica induz a resultados positivos para as questões sociais, não só para os trabalhadores rurais, mas também para o pecuarista e seus familiares. Assim como na análise de impacto ambiental, na análise social cada indicador apresentou sua parcela de responsabilidade para compor o índice geral médio de impacto ambiental. Para uma melhor compreensão e análise da tecnologia avaliada, é necessário o estudo em particular de cada indicador; estes indicadores foram divididos em cinco grupos. 


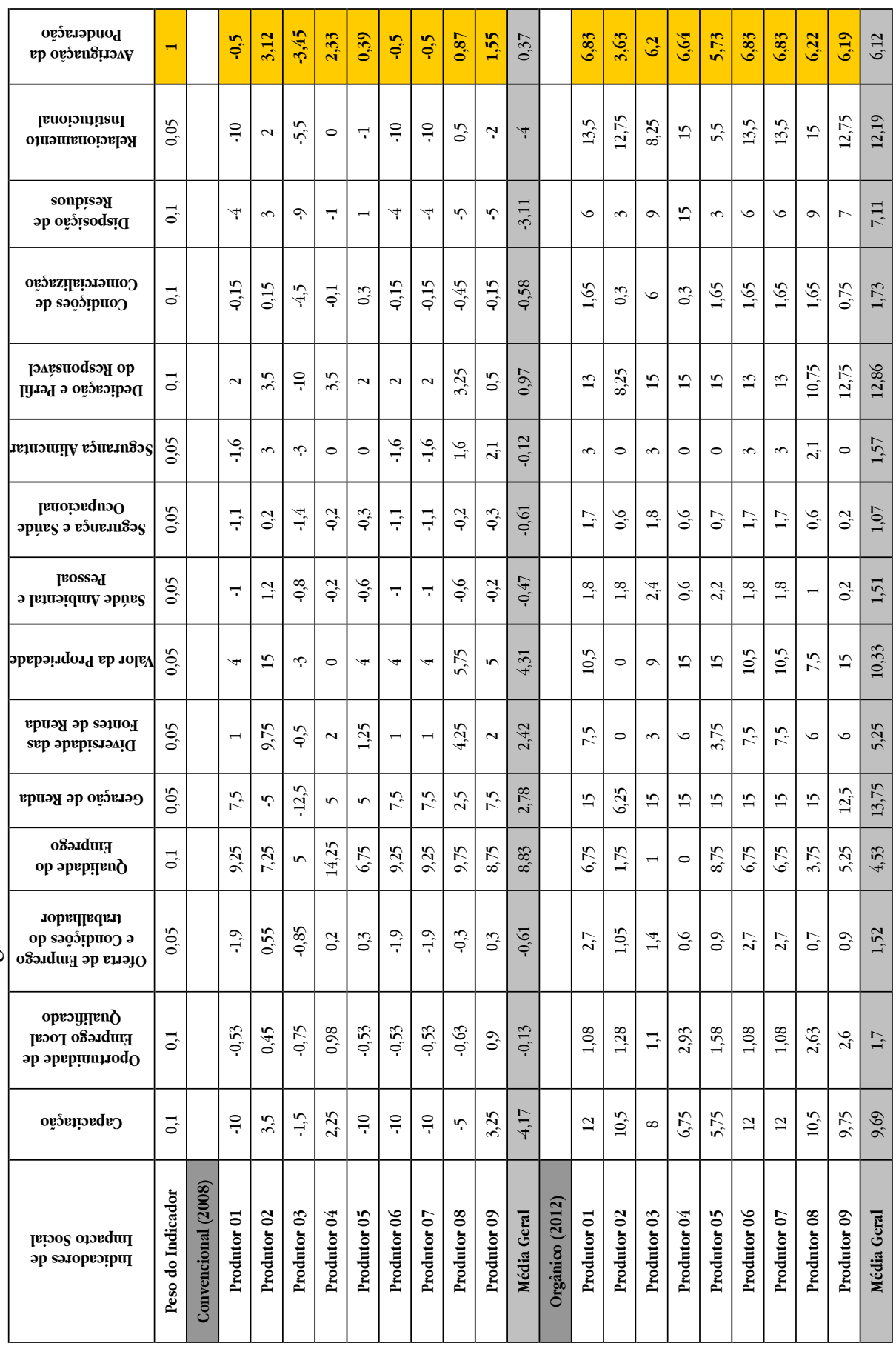




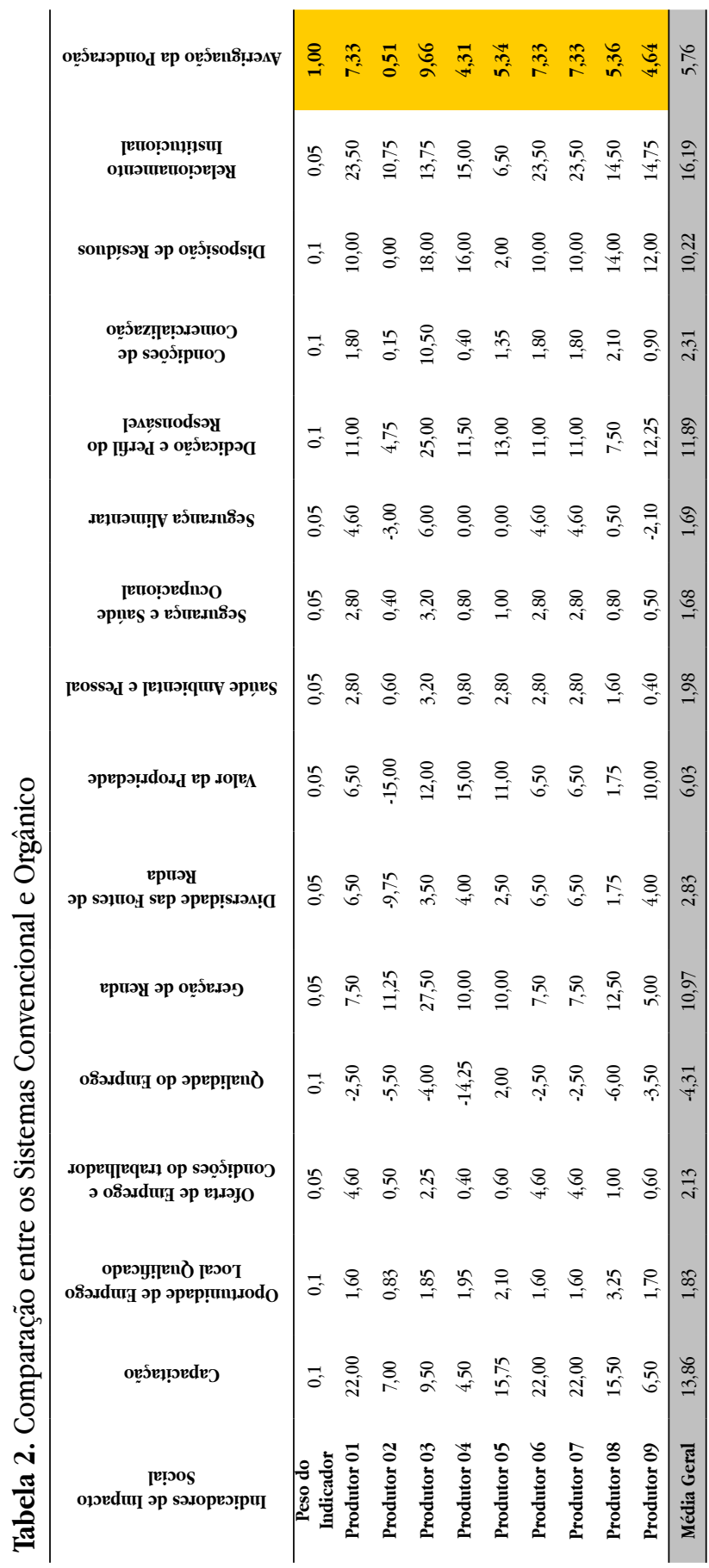




\subsection{FATORES DE EMPREGO}

No grupo fatores de emprego, foram consideradas as quatro variáveis relacionadas ao trabalhador rural. O primeiro índice analisado neste grupo é a capacitação, onde a variação entre a forma de produção convencional $(\mu=-4,17)$ e a forma de produção orgânica $(\mu=9,69)$ atinge a segunda maior variação de toda a Tabela $2(\mu=13,86)$; esta variação demonstra a necessidade de mão de obra mais qualificada na produção orgânica, seja mão de obra direta seja indireta. Comparando com pesquisas anteriores que utilizam o mesmo método de análise para mensurar os impactos sociais na produção orgânica, Rodrigues (2006), Barreto (2010) e Silva (2011) obtiveram os valores para o índice capacitação de $(\mu=9,00)$, $(\mu=6,11)$ e $(\mu=6,29)$, respectivamente.

O valor encontrado por Rodrigues (2006) é o mais próximo ao encontrado na pesquisa sobre a pecuária bovina de corte orgânica no Brasil. $O$ índice oportunidade de emprego local qualificado obteve a variação de $(\mu=1,83)$ e o índice oferta de emprego e condições do trabalhador registrou a variação de $(\mu=2,13)$. $\mathrm{O}$ quarto índice avaliado neste grupo foi a qualidade do emprego, que apresentava na pecuária convencional o índice médio de $(\mu=8,83)$ e na produção orgânica o índice médio obteve uma redução para $(\mu=4,53)$, sendo a variação média de $(\mu=-4,31)$, ressaltando que este índice é o único que se apresenta negativo na comparação entre as duas formas de produção.

Procedendo-se uma primeira análise em relação à mão de obra local relatada nas entrevistas com os pecuaristas, nota-se que há uma grande necessidade de utilização de mão de obra mais qualificada na pecuária orgânica, devido às instruções normativas que devem ser seguidas, sendo a alfabetização uma necessidade básica da mão de obra direta, onde é relatada pelos entrevistados a dificuldade de encontrar, muitas vezes, profissionais com este mínimo de qualificação.

Outros dois pontos citados nas entrevistas por grande parte dos pecuaristas é o fato da mão de obra local ser "nômade", onde muitas vezes estes funcionários não permanecem no emprego por muito tempo, dificultando a manutenção do aprendizado para a produção orgânica. E o outro ponto é o fato de que os funcionários rurais, muitas vezes, não querem mais morar no campo, migrando com 
as famílias para a área urbana, sendo um dos grandes problemas enfrentado pelos produtores de carne bovina orgânica.

\subsection{FATORES DE GERAÇÃO DE RENDA}

Foram agrupados três índices relacionados à geração de renda: geração de renda propriamente dita, diversidade das fontes de renda e valor da propriedade. A geração de renda na produção convencional obteve a média de $(\mu=2,78)$, passando para $(\mu=13,75)$ na produção orgânica, sendo a variação de $(\mu=10,97)$. Nesta variação fica evidente a melhoria da renda do produtor rural com a produção orgânica, onde foi relatado nas entrevistas a garantia da venda e do recebimento, através de contrato firmado com o grupo JBS, onde os produtores orgânicos recebem na venda $10 \%$ a mais pelo valor da arroba do dia para os machos e $18 \%$ a mais pelas fêmeas até 04 anos.

Neste mesmo índice, Barreto (2010) obteve em sua pesquisa o valor de ( $\mu$ $=12,68)$. Nas pesquisas realizadas por Rodrigues (2006) e Silva (2011), os valores encontrados para o índice geração de renda na produção orgânica foram de $(\mu=$ $10,00)$ e $(\mu=12,68)$. A geração de renda na produção orgânica se evidencia quando se analisam as quatro pesquisas citadas, demonstrando que a produção orgânica é rentável.

$\mathrm{Na}$ realização das entrevistas, os produtores 02, 03, 04, 08 e 09 enfatizaram que, com a produção orgânica, os custos de produção são reduzidos, quando comparados aos da pecuária bovina convencional. Para estes produtores, com o ecossistema já adaptado, os custos com medicamento, ração, suplementação e manutenção das pastagens ficam reduzidos, sendo o custo fixo o único que apresenta uma pequena elevação na produção orgânica. Com o custo de produção reduzido e com o ganho a mais pela arroba na comercialização da carne orgânica, a lucratividade da pecuária bovina orgânica fica evidente.

O segundo índice é a diversidade das fontes de renda, sendo a variação entre as duas formas de produção de $(\mu=2,83)$; este número relativamente baixo foi encontrado porque na produção convencional alcançava $(\mu=2,42)$, já com a implementação de práticas de produção orgânica, atingiu o valor de $(\mu=5,25)$. O 
terceiro índice é o valor da propriedade, obtendo a variação de $(\mu=6,03)$, quando na produção convencional era de $(\mu=4,31)$, passando na produção orgânica para $(\mu=10,33)$.

Ao analisar em sua pesquisa o índice valor da propriedade, Rodrigues (2006) chegou ao valor de $(\mu=4,69)$; nas pesquisas realizadas mais recentemente, Barreto (2010) e Silva (2011) obtiveram, respectivamente, os valores de $(\mu=9,21)$ e $(\mu=$ $9,22)$ para o índice valor da propriedade.

A valorização das propriedades com a certificação é evidente, mas o índice não foi elevado somente por este fato, o valor das propriedades, em geral, vem crescendo com o passar dos anos, contribuindo para a elevação do índice em questão.

\subsection{FATORES DE SAÚDE NO AMBIENTE DE TRABALHO}

Relacionados à saúde no ambiente de trabalho estão os índices saúde ambiental e pessoal, segurança e saúde ocupacional, segurança alimentar e disposição de resíduos. $O$ índice saúde ambiental relacionado à produção convencional apresenta como índice médio o valor de $(\mu=-0,47)$, quando a produção passa para orgânica, este índice passa para $(\mu=1,51)$, registrando uma variação média de ( $\mu$ $=1,98)$.

O índice segurança e saúde ocupacional obteve uma variação média entre as duas formas de produção de carne bovina de $(\mu=1,68)$, e o índice segurança alimentar registrou $(\mu=1,69)$ na variação entre a produção convencional e a orgânica.

O quarto e último índice relacionado à saúde no ambiente de trabalho trata da disposição dos resíduos. A variação deste índice se encontra entre as cinco maiores da Tabela 2 , gerando a variação média de $(\mu=10,22)$, onde, na produção convencional, o índice obteve $(\mu=-3,11)$, passando para $(\mu=7,11)$ na pecuária bovina de corte orgânica.

A maior expressão deste fator se dá pelo índice disposição de resíduos, que na pesquisa de Rodrigues (2006) obteve o valor de $(\mu=2,50)$. Na pesquisa realizada por Barreto (2010) o mesmo índice em questão apresentou o valor de $(\mu$ 
$=5,00)$ e Silva (2011) demonstra como resultado deste índice o valor de $(\mu=5,00)$. A pecuária bovina de corte orgânica é que apresenta o maior valor para o índice disposição de resíduos, obtendo o valor de $(\mu=7,11)$ conforme demonstrado.

Uma das preocupações na produção orgânica é o destino final dos resíduos utilizados na produção, bem como a disposição sanitária do recinto e até mesmo o uso de coleta seletiva pelos proprietários, colaborando de forma efetiva para que os resíduos sejam entregues de maneira correta no meio urbano.

\subsection{FATORES DEDICAÇÃO E PERFIL DO RESPONSÁVEL}

Apenas o índice dedicação e perfil do produtor é analisado neste fator, índice que considerando a pecuária convencional gerou o valor de $(\mu=0,97)$, saltando para $(\mu=12,86)$ na pecuária orgânica. A média entre as duas formas de produção apresenta-se como a terceira maior de toda a Tabela 2, gerando o valor de $(\mu=11,89)$.

$\mathrm{O}$ índice que mede a dedicação e perfil do produtor se apresenta como uma grande mudança na pecuária orgânica, em pesquisas realizadas anteriormente por outros autores. Rodrigues (2006), analisando a pecuária leiteira na agricultura familiar na região de Votuporanga (SP), obteve o valor de $(\mu=9,13)$ para este índice. Na pesquisa realizada por Barreto (2010) sobre o manejo agroecológico da caatinga em unidades familiares no RN, o índice em questão apresentou o valor de $(\mu=8,54)$. Silva (2011), ao pesquisar a produção orgânica em unidades familiares no semiárido brasileiro, chega ao valor de $(\mu=8,54)$ para este índice.

Nas entrevistas, os produtores relatam que a mudança para a pecuária orgânica trouxe um maior engajamento familiar na atividade, uma maior capacitação dirigida para a atividade, um aumento das horas de permanência na propriedade e $o$ uso de um sistema de certificação que, para eles, é o diferencial na comercialização do produto, bem como pela maior exigência da permanência do agricultor no estabelecimento, devido às práticas e cuidados de manejo que são corriqueiros, e do aumento das atividades agropecuárias desenvolvidas no sistema. Segundo Gazolla (2004), essa maior dedicação pode ser também explicada pela maior demanda de atividades, ou seja, aumento de serviços especializados advindos do manejo orgânico. 


\subsection{COMERCIALIZAÇÃO E ASPECTOS INSTITUCIONAIS}

Dois índices foram relacionados, condições de comercialização e relacionamento institucional. $\mathrm{O}$ índice condições de comercialização tratando de pecuária convencional gerou uma média de $(\mu=-0,58)$, passando para $(\mu=1,73)$ quando os produtores adquirem a certificação para a produção orgânica, sendo a variação média entre as formas de produção de $(\mu=2,31)$. Resultado muito próximo ao encontrado por Rodrigues (2006), que obteve o valor de $(\mu=1,95)$ para o índice condições de comercialização. Nas pesquisas realizadas por Barreto (2010) e Silva (2011) o valor encontrado para este índice em questão foi o mesmo $(\mu=6,15)$.

O ponto principal para a elevação deste índice é obtido pela cooperação entre os produtores associados à $\mathrm{ABPO}$, tendo a certeza da comercialização de seu produto.

O índice que obteve a maior variação da tabela, que foi de $(\mu=16,19)$, trata do relacionamento institucional, passando de $(\mu=-4,00)$ quando a produção era convencional, para $(\mu=12,19)$ com a produção de maneira orgânica. Nas pesquisas realizadas para a produção orgânica, Barreto (2010) e Silva (2011) apresentam o mesmo valor para este índice $(\mu=5,25)$.

Novamente a pesquisa que apresenta um valor mais equiparado ao valor encontrado na atual pesquisa para o índice relacionamento institucional, que é de $(\mu=12,19)$, foi a pesquisa de Rodrigues (2006), que apresentou a variação média de $(\mu=11,81)$ para o índice em questão.

No sistema Ambitec este índice é resultante de seis variáveis: utilização de assistência técnica, cooperativismo, filiação tecnológica nominal, utilização de vistorias, capacitação do gerente da propriedade e utilização de empregados especializados.

Dentre as variáveis do índice relacionamento institucional, a única que não foi citada como utilizada pelos produtores foi a filiação a uma tecnologia nominal; as cinco variáveis restantes foram de grande valia para os produtores e com isso fizeram deste índice o de maior destaque da tabela. A pecuária orgânica depende muito destas cinco variáveis, seja pela exigência da certificação e de utilização de assistência técnica na produção, seja pela necessidade de especializar a mão de obra empregada na propriedade. 


\subsection{COMPARAÇÃO ENTRE OS PRODUTORES}

$\mathrm{Na}$ comparação entre os nove produtores para o impacto social, estes foram agrupados em clusters. No primeiro cluster estão agrupados os produtores 01,06 e 07 . Estes três produtores obtiveram o resultado final no índice geral do impacto social da produção orgânica igual a $(\mu=6,83)$, se caracterizando pelo grupo com a obtenção da maior média, demonstrando a maior preocupação com os impactos sociais (Figura 2).

Os três produtores citados neste cluster são os pioneiros, entre os nove entrevistados, na produção de carne bovina orgânica. Fazem parte de uma mesma família com tradição na pecuária desde 1920 e, somando os três produtores, o rebanho total chega a 18 mil cabeças e 38 mil alqueires de terra, tudo já certificado.

Entre as boas práticas na mensuração dos impactos sociais, este grupo se destaca no aumento de capacitação dos próprios proprietários e também da mão de obra utilizada nas fazendas, como a maior oferta de emprego e melhoria das condições de vida dos funcionários. Estes produtores também citam o aumento da geração de renda como o fator mais atrativo para a produção de carne bovina orgânica.

No segundo cluster foram agrupados os produtores $04,05,08$ e 09 . Estes quatro produtores obtiveram o resultado final no índice geral do impacto social da produção orgânica entre $(\mu=5,64)$ e $(\mu=6,22)$. Este cluster não se diferencia muito do primeiro nas boas práticas na produção. Neste grupo, a preocupação com a capacitação entre os envolvidos foi o fator de destaque.

$O$ índice que mais se destaca neste cluster é o valor da propriedade, que influenciou muito na geração do índice final destes produtores. Acontecendo a valorização normal de mercado, como ocorre normalmente, e a valorização de mercado após a propriedade receber o selo de certificação para a produção orgânica. 


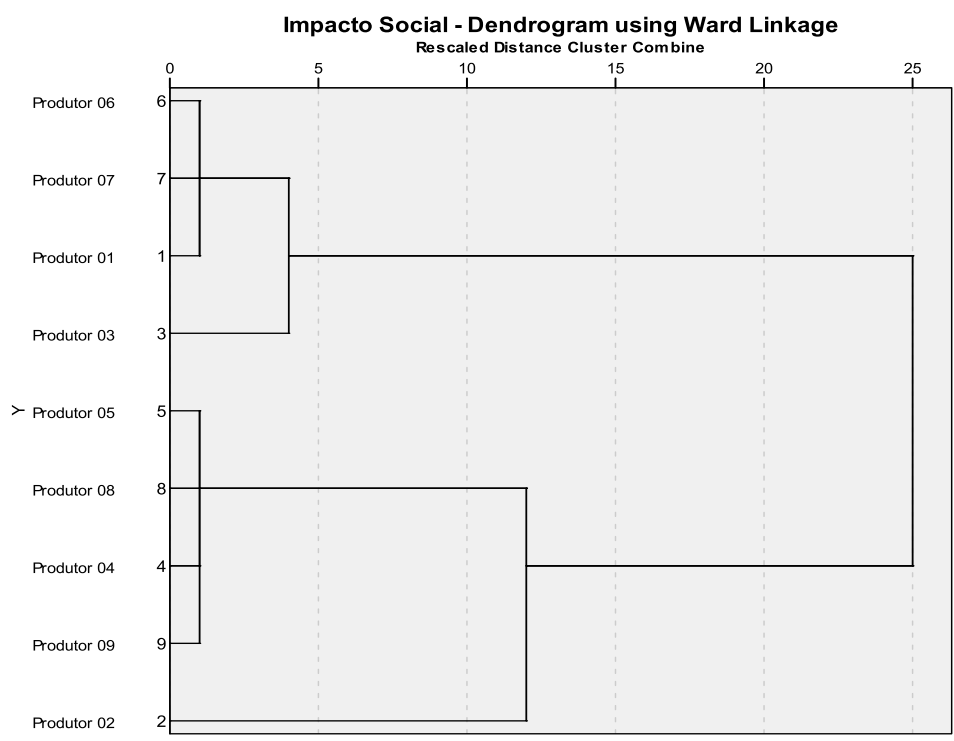

Figura 2. Dendrograma de análise de agrupamentos (Cluster) com base nos índices de impacto social de produtores de carne orgânica no período de 2008-2012 no Brasil.

O terceiro cluster é formado pelo produtor 03 . Este produtor obteve o resultado final no índice geral do impacto social da produção orgânica igual a ( $\mu$ $=6,20)$. As principais diferenças entre este produtor e os demais entrevistados são que este é o único produtor que utiliza para a produção terra em forma de arrendamento. A mão de obra quando utilizada por este produtor é em forma de diarista, não tendo vínculo empregatício e a forma de produção é feita somente com a recria e engorda. Para isto, este pecuarista compra os bezerros desmamados dos próprios associados da $\mathrm{ABPO}$.

O quarto e último cluster é formado pelo produtor 02. Este produtor obteve o resultado final no índice geral do impacto social da produção orgânica igual a ( $\mu$ $=3,63$ ), sendo o menor valor entre todos os entrevistados. O produtor 02 é o mais novo associado da $\mathrm{ABPO}$, tinha acabado de receber a certificação quando foi feita a entrevista (maio de 2012). Em comum às respostas dos outros entrevistados, o produtor 02 cita a maior dedicação do responsável e a maior capacitação dos envolvidos na produção orgânica. Em relação à geração de renda, condições de comercialização e valorização da propriedade, o mesmo não tinha certeza dos 
resultados que iria obter com a produção orgânica, sendo o principal motivo do menor resultado entre os nove pecuaristas.

\section{CONSIDERAÇÕES FINAIS}

A transição para a produção orgânica demonstrou que contribui para o incremento e a distribuição da receita nas unidades familiares, gerando impacto econômico. Observou-se que todos os indicadores de impacto social foram positivos, trata-se de uma clara demonstração de que, na percepção dos produtores rurais, estes encontraram uma nova identidade para suas propriedades e para eles próprios. A utilização de práticas agroecológicas associadas à produção orgânica fomenta a diversificação das atividades pecuárias. Este fator foi percebido como uma maneira de se reduzir os riscos ao se envolverem com uma atividade especializada como esta, que ocupa um nicho específico de mercado.

Os indicadores Geração de Renda, Capacitação, Dedicação e Perfil do Responsável e o Relacionamento Institucional foram os que mais contribuíram para o impacto social positivo na utilização do manejo agroecológico. Deve-se ressaltar que os pecuaristas orgânicos informaram que perceberam uma queda nos custos de produção. Trata-se, portanto, de uma grande vantagem, uma vez que estes mesmos pecuaristas conseguiram uma remuneração maior para seus produtos, quando celebraram um acordo de fornecimento regular com uma grande empresa internacional de abate de bovinos.

Esta grande multinacional, por sua vez, oferece garantias para a comercialização da produção, além de remunerar com preços mais elevados que os preços praticados no mercado de carne bovina convencional.

Estabeleceu-se um canal privilegiado de comercialização, onde o produto orgânico é identificado com destaque nos pontos de varejo. A longo prazo, a renda deste grupo de produtores é afetada positivamente com a maior valorização das propriedades. Isto acontece principalmente após esta receber o selo de produção orgânica.

A produção orgânica deve estar embasada em princípios agroecológicos 
para garantir sustentabilidade socioeconômica. $\mathrm{O}$ real engajamento dos pecuaristas e de suas famílias com as atividades diárias da propriedade e a busca de uma maior capacitação sobre o tema ajudaram a conquistar e consolidar esta maior sustentabilidade socioeconômica.

Um ponto forte desta pesquisa foi conseguir entrevistar um número de produtores rurais que se aproxima do universo total de pecuaristas orgânicos no país. Como limitação da pesquisa deve ser ressaltado que foi feita apenas uma entrevista e aplicação de questionário por organização.

Para futuras pesquisas sobre o tema, sugere-se o aprofundamento das análises de custo das atividades de produção de carne bovina orgânica. Seria oportuno também ampliar o número total de pecuaristas acessados. Além disso, o emprego de instrumentos analíticos relacionados à agregação de valor das operações de produção também poderia trazer um grande ganho para o debate científico.

\section{REFERÊNCIAS}

ARAÚJO, G. C. de; MENDONÇA, P. S. M. Análise do processo de implantação das normas de sustentabilidade empresarial: um estudo de caso em uma agroindústria frigorífica de bovinos. RAM. Revista de Administração Mackenzie (Online), v. 10, p. 31-56, 2009.

ASSOCIAÇÃO BRASILEIRA DAS INDÚSTRIAS EXPORTADORAS DE CARNES - ABIEC.

Estatísticas. Disponível em: <www.abiec.com.br > . Acesso em: 22 ago. 2011.

ASSOCIAÇÃO BRASILEIRA DE PECUÁRIA ORGÂNICA - ABPO. Disponível em: $<$ www.abpopantanalorganico.com.br>. Acesso em: 10 abr. 2012.

BARRETO, H. F. M. Impactos econômicos do manejo agroecológico da caatinga em unidades de produção familiar no Oeste Potiguar. 2010. 143f. Dissertação (Mestrado em Ciência Animal) - Universidade Federal Rural do Semiárido (UFERSA), Mossoró, 2010.

BINOTTO, E.; NAKAYAMA, M. K. Um método de análise da criação de conhecimento para a realidade dos agronegócios. REAd Revista Eletrônica de Administração, v. 
15 , p. 1-29, 2009.

BRASIL. Instrução Normativa no 46/2011. Disponível em: < https://docs. google.com/document/d/108XBLL7I_1zvCafSAhiQzHs37y8ZEyR840GcpoqOJmg/ edit?hl=pt_BR\&pli=1>. Acesso em: 18 abr. 2012.

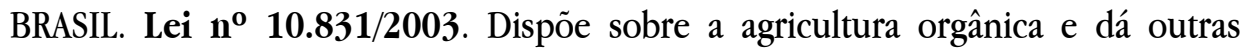
providências. Disponível em: <http://www.planalto.gov.br/ccivil_03/leis/2003/ 110.831.htm > . Acesso em: 18 abr. 2012.

BUAINAIN, A. M.; GUANZIROLI, C.; SOUZA FILHO, H. M. de; BÁNKUTI, F. I. Peculiaridades regionais da agricultura familiar brasileira. In: SOUZA FILHO, H. M. de; BATALHA, M. O. (Org.). Gestão integrada da agricultura familiar. São Carlos: Ed. da UFSCar, 2005.

DENARDI, R. A.; HENDERIKX, E. M. G. J.; CASTILHOS, D. S. B.; BIANCHINNI, V. Fatores que afetam o desenvolvimento local em pequenos municípios do Estado do Paraná. Curitiba: EMATER-PR, 2000.

FIGUEIREDO, E. A. P. de; SOARES, J. P. G. Sistemas orgânicos de produção animal: dimensões técnicas e econômicas. In: REUNIÃO ANUAL DA SOCIEDADE BRASILEIRA DE ZOOTECNIA, 49., 2012, Brasília. Anais... Brasília, DF: SBZ, 2012.

GAZOLLA, M. Agricultura familiar, segurança alimentar e políticas públicas: uma análise a partir da produção para autoconsumo no território do Alto Uruguai/ RS. 2004. 286f. Dissertação (Mestrado) - Faculdade de Ciências Econômicas, Universidade Federal do Rio Grande do Sul, Porto Alegre, 2004.

GEHLEN, I. Políticas públicas e desenvolvimento social rural. São Paulo em Perspectiva, São Paulo, v. 18, n. 2, p. 95-103, abr./jun. 2004.

HAIR JUNIOR, J. F.; BLACK, W. C.; BABIN, B. J.; ANDERSON, R. E.; TATHAM, R. L. Análise multivariada de dados. 5. ed. Porto Alegre: Bookman, 2005.

INSTITUTO BRASILEIRO DE GEOGRAFIA E ESTATÍSTICA - IBGE. IBGE notícias. 
Disponível em: <http:/www.ibge.gov.br/home/presidencia/noticias/noticia visualiza.php?id_noticia $=2107 \&$ id_pagina=1>. Acesso em: 25 nov. 2012.

INSTITUTO BIODINÂMICO - IBD. Associação de certificação Instituto Biodinâmico. IBD Certificações. Disponível em: < http://www.ibd.com.br > Acesso em: 30 nov. 2011.

PAULUS, G.; SCHLINDWEIN, S. L. Agricultura sustentável ou (re)construção do significado de agricultura? Revista Agroecologia e Desenvolvimento Rural Sustentável, Porto Alegre, v. 2, n. 3, p. 44-52, jul./set. 2001.

RODRIGUES, G. S. Avaliação sócio ambiental da integração tecnológica EMBRAPA pecuária sudeste para produção leiteira na agricultura familiar. Agricultura em São Paulo, São Paulo, v. 53, n. 2, p. 35-48, jul./dez. 2006.

RODRIGUES, G. S. Métodos para avaliação de impactos de pesquisa - dimensão ambiental: sistema de avaliação de impacto ambiental da inovação tecnológica para produção animal (AMBITEC - Produção Animal). Jaguariúna: EMBRAPA Meio Ambiente, 2002. (Planilha Microsoft Excel ${ }^{\circledR}$ ).

RODRIGUES, G. S.; CAMPANHOLA, C.; KITAMURA, P. C. Avaliação de Impacto Ambiental da Inovação Tecnológica Agropecuária: AMBITEC-AGRO. Jaguariúna: EMBRAPA, 2003. 95p. (Documentos, 34).

RODRIGUES, G. S.; CAMPANHOLA, C. Sistema integrado de avaliação de impacto ambiental aplicado a atividades do Novo Rural. Pesquisa Agropecuária Brasileira, v. 38, p. 445-451, 2003.

SILVA, A. C. C. Impactos ambientais da produção orgânica animal em unidades familiares nas regióes Semiárida brasileira e Toscana-Itália. 2011. $135 \mathrm{f}$. Dissertação (Mestrado em Produção Animal) - Universidade Federal do Rio Grande do Norte (UFRN)/Universidade Federal Rural do Semiárido (UFERSA), Mossoró, 2011.

SOARES, J. P. G.; AROEIRA, L. J. M.; FONSECA, A. H. F.; FAGUNDES, G. M.; SILVA, J. 
B. Produção orgânica de leite: Desafios e perspectivas. In: SIMPÓSIO NACIONAL DE BOVINOCULTURA LEITEIRA, 3., SIMPÓSIO INTERNACIONAL DE BOVINOCULTURA LEITEIRA, 1., 2011, Viçosa. Anais... Viçosa: Suprema, 2011. v. 1, p. 13-43.

TUPY, O.; PRIMAVESI, O. Avaliação dos impactos econômicos, sociais e ambientais de tecnologias da Embrapa Pecuária Sudeste: 3. Análise estratégica de custos de produção de leite. São Carlos: Embrapa Pecuária Sudeste, 2006. 23p. (Documentos, 56).

WHEELWRIGHT, S. C. Manufacturing strategy: defining the missinglink. Strategic Management Journal, v. 5, n. 11, p. 77-91, 1984.

Recebido em: 17 de outubro de 2013 Aceito em: 01 de dezembro de 2014 